\title{
Oficina de Produção: uma ferramenta de escrita coletiva de documentos multimídia acessível a PNEs.
}

\author{
Lucila Maria Costi Santarosa ${ }^{1}$ - lucila.santarosa@ufrgs.br
}

Lourenço de Oliveira Basso ${ }^{2}$ - lourencobasso@gmail.com

\footnotetext{
${ }^{1}$ Doutora em Educação. Professora/Pesquisadora do Programa de Pós Graduação em Educação-PPGEDU- e de Informática na Educação-PGIE- da Universidade Federal do Rio Grande do Sul.

${ }^{2}$ Doutorando em Informática na Educação no PPGIE/UFRGS
}

Resumo

O presente artigo apresenta uma ferramenta "Oficina de Produção" para escrita coletiva/individual de documentos multimídias para ser inserida no contexto do Ambiente Virtual de Aprendizagem e Convivência - Eduquito, estabelecendo-se também como um recurso acessível para pessoas com necessidades especiais (PNEs). A ferramenta tem como princípios básicos a flexibilidade, a interatividade, a colaboração/cooperação, a acessibilidade, a expansibilidade, a portabilidade e a reusabilidade. Espera-se que essa ferramenta contribua para a redução das barreiras entre indivíduos e tecnologia, estabelecendo-se como mais uma iniciativa no sentindo de promover a inclusão social e digital de PNEs, através de atividades que envolvam a produção textual, estimulando o seu desenvolvimento cognitivo e sócio-afetivo.

Palavras-chaves: Escrita coletiva; Acessibilidade; Inclusão; PNEs

\section{Oficina de Produção: an accessible tool for collective writing of multimedia documents for people who have special needs.}

\begin{abstract}
This present paper presents a tool called "Oficina de Produção" which is used for collective and/or individual writing of multimedia documents which will be posted on Learning management system - Eduquito. Thus, this specific tool also becomes an accessible resource for people who have special needs. Flexibility, interactivity, cooperation, accessibility, expandability, portability and reusability are some of the basic principles of the tool itself. "Oficina de Produção" is expected to contribute to the decrease of barriers between people and technology, promoting social and digital inclusion to people who have special needs while making use of writing activities and stimulating their cognitive and socio-affective development.
\end{abstract}

Keywords: Colective writing; Accessibility; Digital inclusion; People with special education needs

\section{Introdução}

As tecnologias digitais prometem suscitar uma transformação radical da vida em comunidade ao permitir ouvir a voz do plural, ao impulsionar uma enunciação coletiva, uma condição-chave para a construção de uma sociedade de plena participação e de igualdade de oportunidade a todos os seus atores sociais. Pela mediação das tecnologias digitais, potencialidades de sujeitos anteriormente colocados na exterioridade dos espaços culturais conquistam visibilidade e, o processo de inclusão de todos efetivamente passa a ser desencadeado.

Diante deste quadro, cresce no mundo todo o número de pessoas com necessidades especiais (PNEs) a reivindicar o seu legítimo direito de acesso à 
informação/formação e a espaços acessíveis às tecnologias digitais. O reconhecimento da diversidade humana apontou para a necessidade de ambientes e ferramentas digitais condizentes com a especificidade de cada indivíduo.

Apesar das crescentes iniciativas no sentido de expandir a inclusão digital a todo cidadão, este processo ainda ocorre de forma muito lenta, especialmente no que se refere à construção de espaços e ambientes digitais acessíveis a PNEs. Neste sentindo, é fundamental contemplar, pelos desenvolvedores das tecnologias de informação e comunicação (TICs), os quesitos que envolvem o conceito de acessibilidade.

$\mathrm{O}$ presente trabalho pretende apresentar o projeto de desenvolvimento de uma ferramenta que visa reduzir a carência de opções de tecnologias acessíveis para construção de documentos multimídias coletiva ou individualmente. A referida ferramenta tem como objetivo propiciar a interação de PNEs, abrindo espaço para o estabelecimento de quadros de cooperação/colaboração no processo de escrita. Buscase, através da utilização da Oficina de Produção dentro do contexto do Ambiente Virtual de Aprendizagem (AVA) Eduquito ${ }^{1}$, um espaço para a produção textual visando o desenvolvimento sócio-cognitivo destes indivíduos, bem como sua inclusão digital e social.

\section{Revisão de conceitos}

Muito se tem pesquisado e desenvolvido atualmente na área de escrita coletiva mediada pelo uso do computador. Neste processo, em que os indivíduos trabalham coletivamente visando o desenvolvimento de um documento único como resultado, o grupo precisa negociar diferenças, checar fontes e lapidar conceitos, mudando o foco da preocupação com a proteção ao nome do autor para o cuidado com a informação, com o texto da comunidade (PRIMO e RECUERO, 2003, p. 61).

Sapsomboon (1997, apud AXT e MARTINS, 2004, p.43), destaca a complexidade envolvida no processo de autoria, onde, além da formulação em texto para expressar idéias, o processo engloba atividades tais como: coleta de dados, formulação de intenções, de planejamento e revisão de metas. No trabalho realizado coletivamente são apresentadas "[...] as complexidades, a um só tempo, da autoria em si e da coordenação de esforços no trabalho em equipe" (p.43). O trabalho em grupo propiciaria aos seus integrantes: "oportunidade para reflexão sobre as opiniões dos outros em contraste com as suas, melhor expressão de seus pensamentos de forma a se fazer compreender por todos, trabalho sobre a aceitação de críticas, respeito mútuo, reciprocidade" (p.44).

Partindo do contexto de autoria coletiva mediada pelo computador e analisando a interação dos indivíduos na construção dos materiais (hipertextos), dá-se destaque para dois conceitos da tipologia proposta por Primo (PRIMO e RECUERO, 2003) para estes documentos: o hipertexto colagem, que constitui uma atividade de escrita coletiva, mas demanda mais um trabalho de administração e reunião das partes criadas em separado; e o hipertexto cooperativo, onde todos os envolvidos compartilham a

${ }^{1}$ Acessível na web através do seguinte endereço: http://solaris.niee.ufrgs.br/ eduquito/

V. 6 № 1, Julho, 2008 
invenção do texto comum, à medida que exercem e recebem impacto do grupo, do relacionamento que constroem e do próprio produto criativo em andamento. Podemos associar a estas duas categorias os conceitos de colaboração e cooperação ${ }^{2}$, respectivamente.

Por questões de facilidade de edição, de controle de versões, documentação, sincronização de atividades e acompanhamento do processo criativo, uma atividade coletiva de autoria é forte candidata a ter um suporte informático (AXT e MARTINS, 2004, p.45). Neste sentido, cita-se como exemplo dentro do Programa de PósGraduação em Informática na Educação (PPGIE) da UFRGS, foram desenvolvidas algumas pesquisas visando implementar editores de textos coletivos. Destacamos aqui o ETC (BEHAR et al., 2006), desenvolvido pelo Núcleo de Tecnologia Digital aplicada à Educação (NUTED); o Equitext (ALONSO et al., 2003), desenvolvido por alunos e bolsistas do PPGIE; e o Eccologos (AXT e MARTINS, 2004), desenvolvido dentro de um projeto do Laboratório de Estudos da Linguagem, Interação e Cognição (LELIC).

Além das ferramentas para construção coletiva de textos, destacamos neste trabalho algumas propostas que oferecem espaço para a criação, ainda que de forma individual, de histórias (em quadrinhos ou em formato de livros digitais). Dentre as ferramentas que se enquadram nesta categoria, cita-se para exemplificar o editor de histórias em quadrinhos Hagaquê (PICONI e TANAKA, 2002), desenvolvido pelo Núcleo de Informática Aplicada à Educação (NIED) da UNICAMP, e o software Fábrica Fantástica (SANTAROSA et al., 1996), desenvolvido pelo Núcleo de Informática na Educação Especial (NIEE) da UFRGS. Dentre as opções comerciais, citamos aqui Quadrinhos da Turma da Mônica ${ }^{3}$ e Comic Life ${ }^{4}$.

Apesar do crescente interesse pelo desenvolvimento de ferramentas para construção coletiva de textos ou histórias, a grande maioria destas não demonstra preocupação específica em apresentar-se como um recurso acessível para a utilização por PNEs.

O conceito de acessibilidade utilizado no presente trabalho contempla a flexibilização do acesso à informação e da interação de PNEs com ambientes digitais/virtuais (GUIA, 2000, apud SANTAROSA et al., 2007). A acessibilidade passa a ser entendida como "um meio de disponibilizar a cada usuário interfaces que respeitem suas necessidades especiais e preferências e de potencializar a construção de um projeto emancipatório que traga em sua essência a ruptura com um modelo de sociedade que fixa limite, subordina e exclui grupos de homens e mulheres dos coletivos inteligentes" (CONFORTO e SANTAROSA, 2002, p. 101).

\footnotetext{
${ }^{2}$ Usamos aqui a definição apresentada por Maçada e Tijiboy (1997), onde a colaboração institui uma relação de ajuda (mútua ou unilateral) na interação. Já na cooperação, além de estarem presentes a interação e a colaboração, deve haver objetivos comuns, atividades e ações conjuntas/coordenadas, pressupondo relações de respeito mútuo e não hierárquicas, posturas de convivência com as diferenças, além de um contínuo processo de negociação.

${ }^{3}$ Uma versão de demonstração do software pode ser obtida através do site http://www.monica.com.br/software/quadrinh.htm

${ }^{4}$ Informações mais detalhadas do software podem ser encontradas no site do seu fabricante: http://plasq.com/comiclife/

V. 6 № 1, Julho, 2008
} 
Apesar do contínuo crescimento da proporção existente do número de computadores por habitantes - no Brasil existiam 150 computadores para cada mil habitantes no primeiro trimestre de 2007 e crescimento interanual de 18,5\% (EVERIS, 2007) -, nota-se que muitas pessoas ainda ficam fora desta expansão tecnológica. Warschauer (2006) destaca que apenas disponibilizar computadores às pessoas não promove a inclusão. Existe a necessidade de realmente fazer com que participem da sociedade da informação e tornem-se aptas a criar novos saberes a partir desta integração, através de recursos acessíveis.

Nota-se uma crescente mobilização no sentido de promover a inclusão digital das PNEs, passando pela atuação de grupos ou $\mathrm{ONGs}^{5}$ dedicadas a estas questões, e chegando às ações de órgãos governamentais. No Brasil, podemos citar como exemplo destas iniciativas, a aprovação do decreto-lei de dezembro de 2004 (conhecido como Lei de acessibilidade), o qual regulamenta o atendimento às necessidades específicas de pessoas portadoras de deficiência (D.O.U., 2004).

Mesmo com estas iniciativas, nota-se que há muito a avançar no sentido de promover a inclusão digital dos PNEs, visto que são escassos os sistemas que favoreçam a aprendizagem e que não apresentem barreiras para sua utilização por PNEs. Destacase aqui o Eduquito (SANTAROSA et al., 2007), um espaço inclusivo para criação de comunidades virtuais de convivência através do desenvolvimento de projetos colaborativos, o qual conta com ferramentas de interação e desenvolvimento, bem como recursos de acessibilidade.

O AVA Eduquito teve sua elaboração fundamentada na abordagem sóciointeracionista proposta por Vygotsky, o qual busca investigar de que forma a interação social promove o desenvolvimento de Funções Psicológicas Superiores (FPS) ${ }^{6}$ no decorrer da vida de um indivíduo (VIGOTSKI, 1998). Segundo o autor, as crianças crescem imersas em um ambiente de constante interação com os adultos, e oferecem ao mundo, inicialmente, respostas dominadas pelos processos naturais. Porém, através da constante mediação dos adultos, processos mentais mais complexos começam a tomar forma. Em um primeiro momento, estes processos funcionam durante a interação das crianças com os outros, principalmente os adultos (processos interpsíquicos), os quais servem de mediadores no contato da criança com o mundo. No decorrer do crescimento, estes processos acabam por ser executados internamente pelas crianças. Isto é, as respostas mediadoras ao mundo transformam-se em um processo intrapsíquico (VIGOTSKII et al., 2006, p. 27). A este processo de apropriação Vygotsky dá o nome de internalização, e destaca também, como parte do mesmo, a reconstrução de operações representantes de atividades externas de forma que as mesmas ocorram internamente (VIGOTSKI, 1998).

\footnotetext{
5 Destacamos aqui, dentre tantos outros, os seguintes grupos: Grupo Português pelas Iniciativas em Acessibilidade (www.acessibilidade.net), Web Accessibility Initiative (http://www.w3.org/WAI/), Núcleo de Informática na Educação Especial (www.niee.ufrgs.br), Acessibilidade Brasil (www.acessobrasil.org.br), Redespecial Brasil (www.redespecial.org.br).

${ }^{6}$ As FPS, ou PPS (Processos Psicológicos Superiores), contemplam as características que diferenciam os seres humanos dos demais animais (VIGOTSKI, 1998).

V. 6 № 1, Julho, 2008
} 
No desenvolvimento das FPS, Vygotsky (1998) destaca o papel fundamental dos instrumentos de mediação. Através destes instrumentos, o indivíduo pode modificar o meio (instrumentos físicos) ou modificar a sim mesmo (instrumentos simbólicos ou signos).

\section{Oficina de Produção: uma proposta acessível}

Analisando sob o ponto de vista do foco deste artigo, pretende-se desenvolver uma nova ferramenta para o estudo da construção coletiva/individual de documentos para ser integrada ao Eduquito ${ }^{7}$, que abre espaço para novas implementações, visto que este AVA tem a acessibilidade como um dos seus pilares de desenvolvimento. Este tipo de ferramenta apresenta-se como um recurso com enorme potencial para explorar o desenvolvimento de indivíduos envolvidos em processos de aprendizagem, uma vez que possibilita o trabalho em grupo, estimula a criatividade e capacidade de abstração. Todas estas características são importantíssimas para o desenvolvimento de qualquer indivíduo, mas apresentam um papel ainda mais fundamental para PNEs (VYGOTSKI, 1997).

Se a apropriação/utilização das TICs, em especial das ferramentas para escrita coletiva de textos, e a interação entre os sujeitos (com e sem necessidades especiais) constituem possibilidades de inclusão social e digital destes, justifica-se a construção de alternativas que possibilitem a redução de obstáculos e de diferenças de oportunidades para PNEs, buscando concentrar a atenção não nas deficiências, mas sim nas suas habilidades, as quais podem "formar a base para o desenvolvimento de suas capacidades integrais" (VIGOTSKII et al., 1988, p. 34).

O desenvolvimento da ferramenta (Oficina de Produção) está planejado para ser realizado em duas etapas: uma fase de modelagem e sua conseqüente implementação. Será desenvolvida baseada na plataforma web, visando a redução dos requisitos necessários para sua utilização e facilitando a integração a AVAs.

Para a fase inicial de modelagem foram levantadas algumas características necessárias ao sistema aqui proposto, as quais são listadas abaixo:

Flexibilidade: a ferramenta deverá permitir que o usuário tenha total liberdade na criação de seu documento, seja através de alterações no seu formato (história, jornal, revista, hq) ou da utilização de elementos (imagens, vídeos, áudios), personalizados ou providos pela ferramenta, para a composição do resultado final.

Interatividade: a ferramenta deverá oferecer a possibilidade de interação do usuário com os elementos e conteúdos cadastrados na base do sistema.

Colaboração/cooperação: o sistema aqui proposto deverá possibilitar a criação coletiva de documentos multimídia, desenvolvido através da interação entre seus usuários.

Acessibilidade: o processo de criação de documentos e os resultados gerados através deste sistema deverão atender aos requisitos necessários para que PNEs

\footnotetext{
${ }^{7}$ A integração da ferramenta aqui proposta ao Eduquito não impede que a mesma possa ser integrada a outros AVAs existentes ou em desenvolvimento.

V. 6 № 1, Julho, 2008
} 
consigam ter acesso a eles sem que sejam prejudicados no decorrer da sua utilização. Toda implementação proposta deverá seguir recomendações de acessibilidade, tanto propostas pela WAI (W3C), quanto sugeridas por pesquisas ligadas à Informática na Educação Especial. Nesta etapa será fundamental a atuação do NIEE, o qual conta uma equipe técnica especializada em programação e acessibilidade. Desta forma, busca-se através da ferramenta promover a integração entre pessoas com as mais diferentes necessidades.

Expansibilidade: a ferramenta deverá possibilitar que sua base de recursos multimídia possa ser permanentemente alimentada com novos materiais, enriquecendo o conjunto de opções para a criação dos documentos.

Portabilidade: a ferramenta deverá oferecer a possibilidade de que os materiais nela produzidos sejam exportados para formatos tais como XML que possam ser visualizados externamente a ela (incluindo todos os recursos que foram utilizados na sua composição), ou que possam ser exportados seguindo algum padrão para compartilhamento de objetos de aprendizagem, tal como o SCORM. Além disso, deverá também oferecer a possibilidade de importação de materiais no referido formato para que os mesmos possam ser editados dentro da ferramenta.

Reusabilidade: o sistema aqui proposto deverá ser projetado de forma que a maior parte de elementos nele utilizados durante a produção de um documento, bem como o resultado final desta produção, possam ser reutilizados para o desenvolvimento de outros documentos.

Para atender às características aqui levantadas, apresenta-se um conjunto de recursos a serem implementados no sistema aqui proposto.

\section{Estrutura em células}

A criação de um documento multimídia, independente do formato escolhido pelo usuário, será constituída pela união de um conjunto de unidades menores aqui denominadas de células. A célula deve constituir-se pela distribuição no seu espaço de elementos (mídias - textos, imagens, vídeos, áudios) que o usuário tem a sua disposição para a criação. Para exemplificar este conceito, podemos citar a criação de um documento no formato de história em quadrinhos (HQ), onde cada quadro será representado por uma célula. Cada célula caracteriza-se como um elemento independente, o qual pode ser utilizado como uma cópia em outros documentos (reusabilidade) e não apenas no documento corrente.

\section{Modelos de documentos}

Para que as células sejam disponibilizadas no espaço de uma página do documento a ser criado, considera-se importante a proposição de modelos com a distribuição destes elementos para que se aproxime mais do formato tradicional do meio escolhido. Para tanto, pensou-se na proposição de modelos de estrutura para criação de documentos multimídia nos seguintes formatos: jornal, revista, história, poesia, roteiros e história em quadrinhos. Estes modelos servirão apenas como guia para o usuário. É importante lembrar que o usuário poderá alterar esta estrutura de distribuição das células no espaço da forma que lhe parecer mais conveniente (flexibilidade), podendo inclusive partir de uma página sem estrutura alguma (página vazia).

\section{Banco de mídias}

O banco de mídias contempla o recurso para o armazenamento dos elementos (mídias) a serem usadas pelos usuários na montagem dos seus documentos. As mídias a 
serem armazenadas podem ser imagens, vídeos, áudios, arquivos de texto, apresentações, etc.

Esta base de recurso apresenta-se em contínuo processo de enriquecimento, através da adição de novos materiais informados pelos usuários, o quais ampliam a base de mídias já existentes na ferramenta, atendendo à necessidade de expansibilidade do sistema.

Ao cadastrar uma nova mídia, o usuário deverá informar um conjunto de palavras associadas ao recurso em questão. Este tipo de procedimento, conhecido como tagging e bastante característico da Web 2.0 (O'REILLY, 2005), auxilia no processo de classificação e busca destas mídias. Estas mesmas informações podem ser utilizadas também para atender às necessidades de acessibilidade dos documentos produzidos, uma vez que podem ser usadas para a descrição da mídia dentro do documento gerado.

\section{Exportação e Importação}

Os recursos de exportação e importação apresentam-se como fundamentais para que os materiais produzidos através da ferramenta possam ser utilizados externamente a ela e também para que possam ser reaproveitados em diferentes momentos, atendendo ao requisito de portabilidade dos documentos produzidos.

Através da exportação de um trabalho produzido, o usuário poderá obter como saída da ferramenta uma versão do documento que conte com todos os recursos nele utilizados. Desta forma, este documento poderá ser acessado em qualquer circunstância, sem que haja a necessidade do documento estar em modo de edição dentro da ferramenta ou a necessidade do mesmo estar armazenado no servidor no qual a ferramenta foi instalada.

Já o recurso de importação apresenta-se como um recurso fundamental para que documentos já finalizados possam ser editados novamente. Para tanto, a ferramenta utiliza o documento final para montar sua estrutura dentro do ambiente de edição. Desta forma, documentos multimídias elaborados com a ferramenta podem ser permanentemente melhorados e expandidos, propiciando assim a reusabilidade destes materiais.

\section{Criação colaborativa/cooperativa}

A ferramenta aqui proposta deve contar com recursos para coordenação de atividades de criação colaborativa e/ou cooperativa de documentos multimídia. Deve ser estudada e adotada uma política de controle das interações (acessos para edição) dos usuários com o documento compartilhado de forma que todos aqueles que tenham permissão possam trabalhar em conjunto.

Destaca-se também dentro do aspecto da colaboração/cooperação, o recurso de comentários oferecido pela ferramenta, o qual permite que usuários registrem suas impressões sobre as células produzidas, sobre as mídias cadastradas na base de dados ou sobre a produção como um todo. Este recurso apresenta importância também em aspectos de motivação e agregação social.

Também considera-se fundamental oferecer recursos de comunicação para que os usuários possam realizar discussões durante o processo de criação dos documentos. Este recurso deve estar presente no AVA ao qual a ferramenta será integrada. Estas discussões poderão ser analisadas em conjunto com os resultados produzidos, a fim de verificar a evolução do trabalho e do conhecimento individual e/ou coletivo dos usuários. 
Por fim, mas não menos importante para este aspecto, destaca-se a possibilidade de consulta e análise do histórico de alterações das células ou da produção como um todo. Desta forma, será possível realizar um acompanhamento da evolução da construção do documento, verificando quais indivíduos contribuíram e a forma como o fizeram.

\section{Pesquisa de conteúdos}

Outro recurso importante de ser destacado dentro da Oficina de Produção referese à possibilidade de consulta aos documentos e células produzidas (ou em produção) dentro da ferramenta, bem como aos elementos cadastrados no Banco de Mídias. As tags (palavras-chave) associadas aos materiais aparecem como elemento fundamental neste ponto. O recurso de pesquisa permitirá aos usuários acesso a toda produção desenvolvida com este sistema e desencadear projetos de novas produções com base nestes materiais.

Atualmente a Oficina de Produção encontra-se em processo de construção, seguindo o princípio de métodos ágeis de desenvolvimento de software (COCKBURN, 2000). A figura 1 apresenta o diagrama de casos de uso preliminar, onde são apresentados os atores e uma macro-visão das suas possíveis ações dentro da ferramenta.

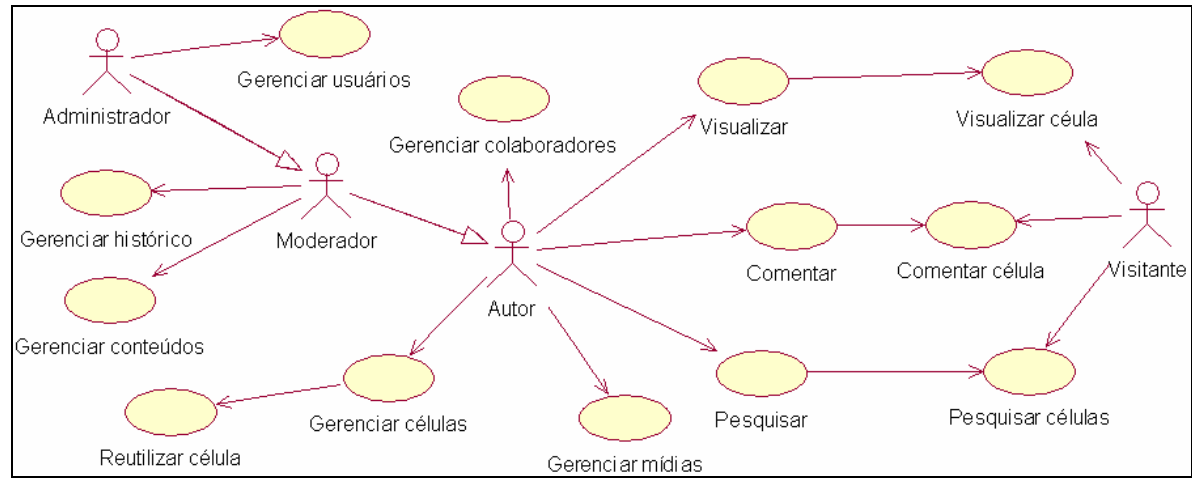

Figura 1 - Diagrama de Casos de Uso Preliminar

\section{Considerações finais}

Espera-se que a ferramenta aqui proposta contribua para a redução das barreiras de interatividade do indivíduo com a tecnologia, e conseqüentemente dos obstáculos presentes na interação entre os sujeitos mediados pelas TICs, estabelecendo-se como mais uma iniciativa no sentindo de promover a inclusão social e digital de PNEs em atividades que estimulem seu desenvolvimento sócio-cognitivo.

Conscientes de que a Sociedade da Informação pode ser construída sob três pilares de exclusão - (1) excluir os que não têm condições econômicas para adquirir os meios tecnológicos adequados; (2) excluir as pessoas que, por idade ou formação, entre outras, não sabem operar com a TICs e (3) excluir as pessoas que por alguma deficiência ou situação de dependência não tem acessibilidade aos recursos tecnológicos - , busca-se oportunizar espaços livres e acessíveis, os quais possam ser utilizados nos mais diversos contextos (familiar, educacionais, profissionais etc.) visando a continua redução desses pilares exclusivos, visto que estas barreiras formam coletivos humanos para os quais não é fácil a integração à Sociedade da Informação. 
Assim, desenvolver uma ferramenta acessível para a produção textual coletiva/individual permitirá oferecer espaço à diversidade humana - ação prioritária para a construção de uma sociedade inclusiva. Conseguir que os benefícios desta nova tecnologia estejam disponíveis para todos significa, no contexto da sociedade atual, um imperativo social e ético. Busca-se, desta forma, avançar no sentindo da construção da sociedade onde cada indivíduo, independentemente das suas características pessoais, tenha as mesmas oportunidades de crescimento e vivência que seus pares.

\section{Referências Bibliográficas}

ALONSO, C. M. M. C.; RIZZI, C. B.; SEIXAS, L. M. J. Software Equitext - Uma ferramenta para escrita colaborativa na web. VIII Taller Internacional de Software Educativo. Novembro, 2003.

AXT, Margarete; MARTINS, Ademir. EccoLogos: autoria coletiva de documentos. Revista Informática na Educação: Teoria e Prática, v. 7, n. 2, p. 39-49, 2004.

BEHAR, P. A.; BITTENCORT, Jossiane; MACEDO, Alexandra Lorandi; BORDINI, Sandra. Escrita Coletiva: o potencial de um Groupware via Web. Renote Revista Novas Tecnologias na Educação, Porto Alegre, v. 4, n. 1, 2006.

COCKBURN, A. Agile Software Development. Cockburn * Highsmith Series Editor, 2000.

CONFORTO, D.; SANTAROSA, L. M. C. Acessibilidade à Web: Internet para todos. In: Revista de Informática na Educação - Teoria E Prática, Pgie/Ufrgs, Porto Alegre, v. 5, n. 2, p. 87-102, nov. 2002.

D.O.U. Diário Oficial da União. Ano CXLI, No- 232, Brasília - DF, Dez. 2004.

EVERIS. Indicador de la Sociedad de la Información (ISI) everis / IESE - Situación de las tecnologías de la Información en Argentina, Brasil, Chile, Colombia y México, ISSN: 1887-6846, MFC Artes Gráficas, S.L. 2007.

O'REILLY, T. What Is Web 2.0 - Design Patterns and Business Models for the Next Generation of Software. O'Reilly Publishing, 2005.

PRIMO, Alex Fernando Teixeira; RECUERO, Raquel da Cunha. Hipertexto Cooperativo: Uma Análise da Escrita Coletiva a partir dos Blogs e da Wikipédia. Revista da FAMECOS, n. 23, p. 54-63, Dez. 2003.

PICONI, A. C.; TANAKA, E. H. . O Uso do HagáQuê Por Alunos Autistas. In: III Congresso Ibero-americano de Informática na Educação Especial, 2002.

SANTAROSA, L. C.; BASSO, Lourenço O.; PASSERINO, Liliana; DIAS, Cristiani O.. Acessibilidade em Ambientes de Aprendizagem por Projetos: construção de espaços virtuais para inclusão digital e social de PNEEs. RENOTE. Revista Novas Tecnologias na Educação, v. 5, n. 1, p. 1-11, 2007.

SANTAROSA, L.M.C.; ORTOLAN,Adriana; BARRIONUEVO,Luis Otávio; PUHL, Roberto; BURMEISTER, Eduardo; PAUL, Klaus. Fábrica Fantástica: Ambiente Hipermídia Lúdico para o Desenvolvimento Cognitivo. Barranquilla/Colômbia, Anais do III Congreso Iberoamericano de Informática Educativa, jul/96 


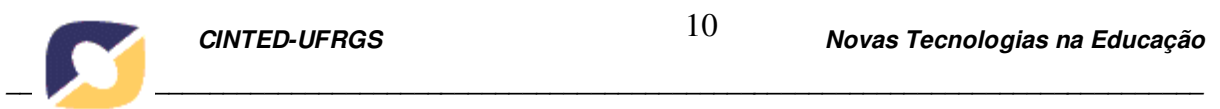

MAÇADA, D. L.; TIJIBOY, A. V. A Colaboração e Cooperação via Internet nas Organizações. Anais do 21 Encontro da ENAMPAD 97 Rio das Pedras/RJ. Set. 1997.

VIGOTSKII, L.S.; LURIA, A. R.; LEONTIEV, A. N. Linguagem, desenvolvimento e aprendizagem. São Paulo: Ícone, 2006.

VIGOTSKI, L. S. A formação social da mente: o desenvolvimento dos processos psicológicos superiores. São Paulo: Martins Fontes, 1998.

VYGOTSKY, L. S Obras Escogidas: Fundamentos de defectología. Tomo V. Madrid: Visor, 1997.

WARSCHAUER, Mark. Tecnologia e Inclusão Social. A exclusão digital em debate. São Paulo: Senac, 2006. 